\title{
Prevalence of lameness and associated risk factors in Canadian Holstein-Friesian cows housed in freestall barns
}

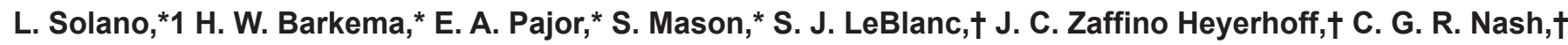 \\ D. B. Haley,† E. Vasseur,ł D. Pellerin,§ J. Rushen,\# A. M. de Passillé,\# and K. Orsel* \\ *Department of Production Animal Health, University of Calgary, Calgary, Alberta, Canada, T2N 4N1 \\ †Department of Population Medicine, University of Guelph, Guelph, Ontario, Canada, N1G 2W1 \\ †Organic Dairy Research Center, University of Guelph, Alfred, Ontario, Canada, K0B 1A0 \\ §Department of Animal Science, Université Laval, Québec, Québec, Canada, G1V OA6 \\ \#Dairy Education and Resource Centre, University of British Columbia, Agassiz, British Columbia, Canada, V0M 1A0
}

\begin{abstract}
Lameness is a severe welfare problem and a production-limiting disease in dairy farming. The objectives of this study were to determine prevalence of lameness and investigate cow- and herd-level factors associated with lameness in dairy cows housed in freestall barns in 3 Canadian provinces. A purposive sample of $40 \mathrm{Hol}-$ stein-Friesian cows was selected from each of 141 dairy farms in Québec, Ontario, and Alberta. In total, 5,637 cows were scored once for lameness (presence of limping when walking). Data collected included information on individual cows (hock lesions, claw length, body condition score, parity, days in milk, and milk production), management practices (floor and stall cleaning routine, bedding routine, and footbath practices), and facility design (stall dimensions, stall base and bedding type, width of feed alley, flooring type, and slipperiness) hypothesized to be risk factors for lameness. Multilevel mixed logistic regression models were constructed (including farm as a random effect and province as a fixed effect). Herd-level lameness prevalence ranged from 0 to $69 \%($ mean $=21 \%)$. Lameness prevalence increased with increasing parity; compared with first parity, cows in parity 2,3 , and $\geq 4$ had $1.6,3.3$, and 4 times, respectively, higher odds of being lame. Furthermore, the odds of lameness were 1.6 times greater in cows with low body condition score $(\leq 2.5)$ than in cows with a higher body condition score. In addition, injured hocks and overgrown claws were associated with 1.4and 1.7-fold increased odds of being lame, respectively, whereas every $1 \mathrm{~kg}$ increase in daily milk production was associated with a $3 \%$ decrease in the odds of being lame. Lameness prevalence was higher in herds with
\end{abstract}

Received March 30, 2015.

Accepted June 20, 2015

${ }^{1}$ Corresponding author: lmsolano@ucalgary.ca $\leq 100$ cows, but lower in barns with a sand or dirt stall base, or with bedding $\geq 2 \mathrm{~cm}$ deep. Cows exposed to very slippery floors had 2 times the odds of being lame compared with cows exposed to nonslippery floors. We attributed the wide range of lameness prevalence to the great variability in facilities and management practices among farms. Finally, we inferred that the prevalence of lameness could be decreased by improving management of multiparous, thin, or injured cows and by adopting management practices intended to improve cow comfort, namely the floor's slip resistance and the stall's lying surface.

Key words: animal welfare, locomotion, dairy cattle, management, cow comfort

\section{INTRODUCTION}

Lameness is one of the most important welfare, health, and productivity problems in intensive dairy farming worldwide. Furthermore, it causes pain (Whay et al., 1998; Rushen et al., 2007), reduces longevity (Booth et al., 2004; Canadian Dairy Information Centre, 2014), milk production (Warnick et al., 2001; Green et al., 2002), and reproductive performance (Hernandez et al., 2001; Garbarino et al., 2004), and consequently has a great economic effect (Ettema and Ostergaard, 2006). The prevalence of lameness varies considerably among farms, regions, and housing systems, although it is generally higher in freestall barns compared with tiestalls (Cook, 2003; Sogstad et al., 2005b), bedded packs (Haskell et al., 2006), and pasture systems (HernandezMendo et al., 2007). In the United States, freestall dairies in Wisconsin and Minnesota had a mean lameness prevalence of 25\% (Cook, 2003; Espejo et al., 2006), whereas in California and the northeastern United States, overall lameness prevalence was estimated to be 34 and 63\%, respectively (von Keyserlingk et al., 2012). British and German studies reported a lameness 
prevalence of 37 and 48\% (Whay et al., 2003; Barker et al., 2010), whereas a prevalence of $16 \%$ was reported in the Netherlands (Amory et al., 2006).

Estimates of the prevalence of lameness using locomotion scores in Canada (irrespective of housing system) are scarce. In Ontario, one study assessed lameness prevalence linked to stall design, but estimated lameness based on the presence of back arch (3.2\%) and claw rotation (23\%) and only in tie-stall barns (Zurbrigg et al., 2005). Another study assessed a wider range of herd-level factors in both tie-stalls and freestalls, but estimated lameness based on the presence of foot lesions (Cramer et al., 2009). The only study that focused on the prevalence of lameness based on locomotion scores in freestalls was conducted in British Columbia (von Keyserlingk et al., 2012). In that study, 35\% of the cows were lame, including $7 \%$ that were severely lame. However, no risk factor analysis was performed. Lameness scoring systems differed considerably among these studies; therefore, the variation in lameness prevalence estimates among European and North American studies could partly be due to methodology and diagnostic criteria.

Several studies reported associations between lameness and factors such as flooring type and slipperiness (Somers et al., 2003; Telezhenko and Bergsten, 2005); the amount, cleanliness, and type of stall bedding (Cook, 2003; Cook et al., 2004a; Ito et al., 2010; Chapinal et al., 2013); stall dimensions (Sogstad et al., 2005a; Espejo and Endres, 2007; Dippel et al., 2009), access to pasture, and footbath frequency (Chapinal et al., 2013). Therefore, differences in lameness estimates among studies could also be attributed to management and housing differences across farms that lead to the presence or absence of risk factors for lameness.

High lameness prevalence estimates and their variation highlight the need for a better understanding of the multifactorial origins of lameness, and the combination of risk factors related to the environment, management, and the individual cow (Vermunt, 2007). Despite increased awareness of lameness as a problem in Canada, apparently no epidemiological study has been done to identify prevalence (and associated risk factor analysis) in freestall barns. Therefore, the objectives were to determine (1) prevalence of lameness, (2) herd-level management and facility design factors related to lameness prevalence, and (3) the association between herd and cow-level factors, as related to the prevalence of lameness.

\section{MATERIALS AND METHODS}

The present study was part of a larger research study examining dairy cow comfort and longevity. Methodol- ogy for farm and cow selection, and assessment of animal-based measures, management practices, and facility design have been described (Zaffino Heyerhoff et al., 2014; Vasseur et al., 2015). Several standard operating procedures were developed and validated as described on the Canadian Dairy Research Portal (https://www. dairyresearch.ca/animal-comfort-tool.php). Based on hypothesized biological cause-and-effect relationships and previous research, a causal diagram was drawn to identify variables to measure on farms and to consider in analyses (Figure 1).

\section{Farms}

A total of 141 freestall dairy farms were enrolled as part of a larger study. Farms were located in 3 Canadian provinces: Alberta $[(\mathbf{A B}) \mathrm{n}=81]$, Ontario $[(\mathbf{O N}) \mathrm{n}=$ 40], and Québec [(QC) $\mathrm{n}=20]$. Data were collected between May 2011 and July 2012 by trained graduate students and research assistants from the University of Calgary (Calgary, AB, Canada), University of Guelph (Guelph, ON, Canada), and Université Laval (Québec City, QC, Canada). Because of practical reasons and availability of students, farms were visited from May 2011 to July 2012 in AB, May to November 2011 in ON, and January to April 2012 in QC. All methods were approved by the Animal Care Committees and Research Ethics Boards of each participating academic institution.

Eligible farms received a recruitment request by mail. Those who were interested replied by mail or fax and had to return a letter indicating willingness to participate in $\mathrm{AB}$ and $\mathrm{ON}$, or they were called by a $\mathrm{DHI}$ (Valacta Inc., Sainte-Anne-de-Bellevue, QC, Canada) advisor in QC. They were then contacted by telephone, after which it was determined whether they met the study criteria. To ensure that participating farms were representative of the majority of freestall herds in Canada, farms had to be enrolled in an organized milk recording system provided by CanWest DHI (Guelph, ON, Canada) or Valacta Inc. and have a herd size $\geq 40$ Holstein-Friesian lactating cows. In ON and QC, farms were also selected on the basis of longevity and having mean milk production $\geq 7,000 \mathrm{~kg} /$ cow per yr (Vasseur et al., 2015). Farms were excluded if lactating cows were subjected to uncommon management practices (e.g., access to an outdoor exercise area or pasture for $>2 \mathrm{~h} / \mathrm{d}$ ). To ensure that animal-based measures reflected housing conditions, the current freestall facility for lactating cows had to be in use for at least $1 \mathrm{yr}$. In Alberta, farm recruitment was also based on participation in the Alberta Dairy Hoof Health Project (Alberta Milk, 2013), a collaborative study that collected data on foot lesions based on the records of professional hoof 


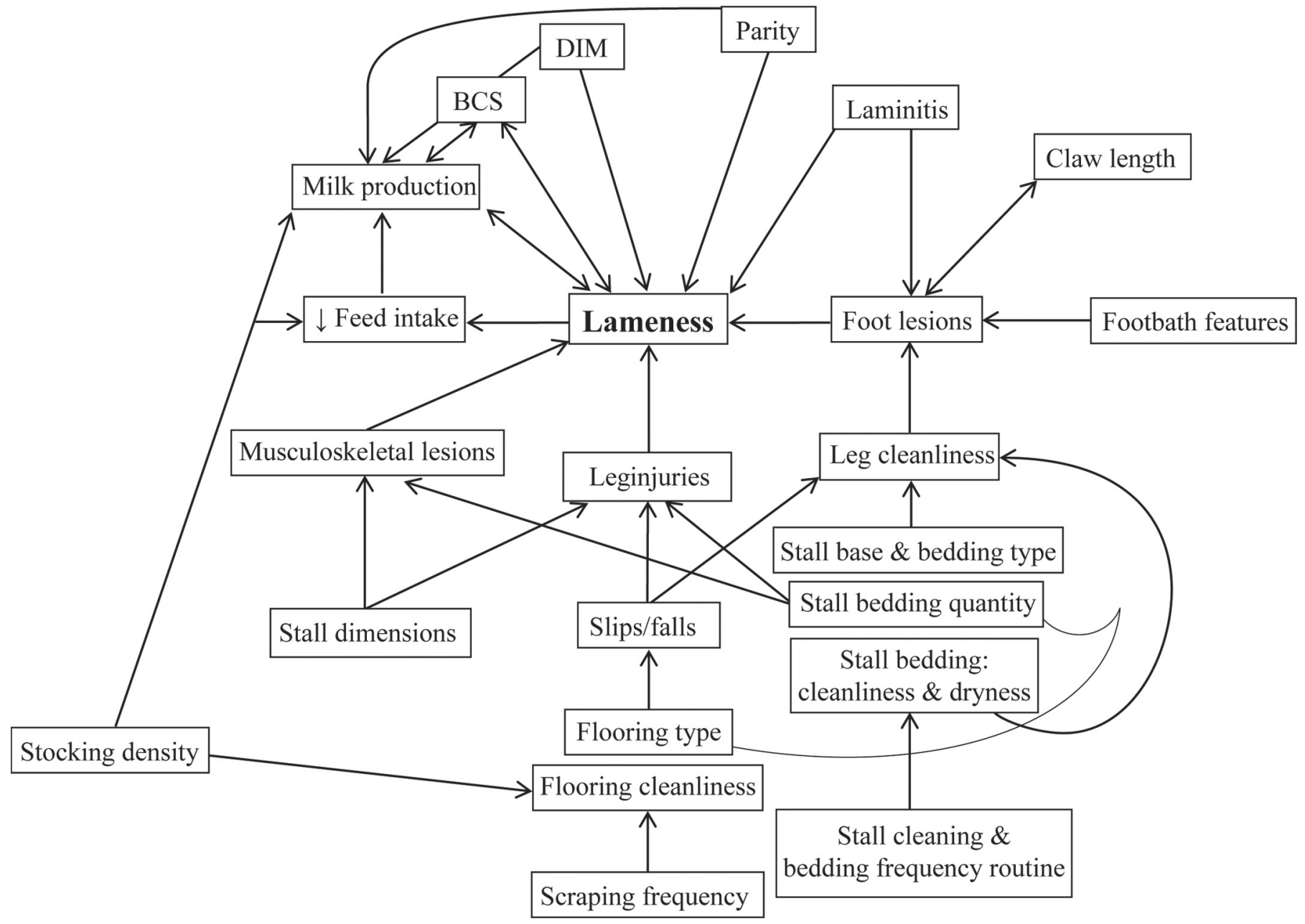

Figure 1. Causal web of factors hypothesized to affect lameness in dairy cows.

trimmers. The sample of farms $(n=158)$ enrolled in The Alberta Dairy Hoof Health Project was representative of the average $\mathrm{AB}$ dairy farm in terms of herd size, breed, type of dairy barn, and longevity (Zaffino Heyerhoff et al., 2014).

\section{Cow Selection}

Based on previous work on estimating sample sizes for cow comfort aspects such as lying behavior (Ito et al., 2009), and due to time constraints (Zaffino Heyerhoff et al., 2014), a purposive sample of 40 lactating Holstein-Friesian cows between 10 and 120 DIM was selected on each farm. This is the period with an increased incidence of lameness (Green et al., 2002). If the herd had $<40$ cows between 10 and 120 DIM, cows $>120$ DIM were sequentially included until 40 cows had been assessed. Conversely, if $>40$ cows between 10 and 120 DIM were present, the sample of study cows was balanced to reflect the proportion of primiparous and multiparous cows in the herd and cows were then randomly selected. Considering the average study farm (Table 1), this sample size represented an average of $29 \%(9-100 \%)$ of the cows present on each farm.

\section{Lameness Assessment}

Training of observers has been described (Gibbons et al., 2012). Briefly, 2 dairy scientists with experience scoring lameness trained 6 observers in the 3 provinces $(3,2$, and 1 observers for $\mathrm{AB}, \mathrm{ON}$, and $\mathrm{QC}$, respectively) during an intensive 2-wk program. To ensure a high level of agreement (weighted Kappa statistic $\geq 0.6$ ), the program included 4 repeatability sessions between trainers and all observers (2 on-farm and 2 with videos) on locomotion scoring. A refresher course and mid-way check (3 to 4 and 5 to 15 wk after initial training, respectively) were done to maintain agreement throughout the study. In addition, $20 \%$ of the videos were re-analyzed by the trainers. The percentage 
exact agreement was calculated as the number of exact agreements/total number of observations $\times 100$.

Cows were video recorded while returning from the milking parlor by 1 or 2 people per farm to assess lameness using a simplified version of a numerical rating score (Flower and Weary, 2006) that was previously validated (Chapinal et al., 2009; Ito et al., 2010). This scoring system aimed to identify cows that were reluctant to bear weight on at least 1 limb (i.e., walked with a limp). A cow was defined as lame if limping was present, which was equivalent to a score of $\geq 3$ on a 5-point scale numerical rating score. Locomotion was not assessed if the video quality was poor, if the cow was trotting or running, or if less than 2 complete strides were recorded $(\mathrm{n}=381)$.

\section{Animal-Based Measures}

Cows were scored for leg cleanliness, BCS, hock injuries, and claw length using standard operating procedures by no more than 2 trained observers per farm. For each of these measures, observers underwent a training program similar to that described above for lameness scoring. Leg cleanliness was assessed using the scoring system adapted from Cook (2006). Cleanliness on the lateral lower hind right leg, from the coronary band to the middle of the tarsal joint, was recorded using a 0 to 3 scale according to the degree of contamination: $0=$ fresh manure for $<50 \%$ of the area; $1=$ fresh manure for $>50 \%$ of the area; $2=$ dried caked and fresh manure for $<50 \%$ of the area; and 3 $=$ entire area with dried caked manure. The BCS was determined as described (Vasseur et al., 2013) using 0.25 increments. Hock injuries were scored in the milking parlor, in the headlocks or where the cows were free to move, as described (Gibbons et al., 2012). In short, conditions of the lateral surface of the left and right tarsal joints were recorded using a 0 to 3 scale: 0 $=$ no swelling, no hair missing; $1=$ bald area with no swelling or swelling $<1 \mathrm{~cm} ; 2=$ medium swelling $(1-2.5$ $\mathrm{cm}$ ), lesion on bald area, or both; and $3=$ major swelling (>2.5 cm; Gibbons et al., 2012). Claw length was assessed in the milking parlor by estimating the angle of the dorsal surface of the left and right lateral claws in relation to the ground. Claw length was defined as no overgrowth (angle $\geq 45^{\circ}$ ) or overgrowth (angle $<45^{\circ}$ ). Individual cow data on parity, DIM, and test-day milk production (measured at the most recent monthly milk recording after data collection) for the sampled cows were obtained from CanWest DHI and Valacta Inc. The average interval between data collection and monthly milk recording was $17 \mathrm{~d}$ (range, 0 to $51 \mathrm{~d}$ ).

\section{General Management}

A questionnaire was administered by interview on every farm. Initially, the questionnaire was pretested on 4 farms to evaluate whether it was understood easily and interpreted correctly. Thereafter, the questionnaire was adapted and improved where necessary. Questions were either open ended (e.g., "Describe the footbath product(s) you use, in what concentration and frequency") or closed ended (e.g., "How often is new bedding added?" "How often do you rake out stalls and remove manure?"; scale of answer: once/d, >once/wk, once/wk, or <once/wk; Vasseur et al., 2015). The questionnaire is available on the Canadian Dairy Research Portal (https://www.dairyresearch.ca/cowcomfort.php\#self).

\section{Facility Design}

Pen Space and Flooring. All environmental measures were collected from all pens where the 40 study cows were housed on the day of the visit. Pens were assessed for type of flooring, width of feed alley, floor cleanliness, and floor slipperiness. Type of flooring was categorized as solid or slatted and concrete or rubber. Feed alley width was measured from the feed bunk to the curb of the stalls. Assessing the cleanliness of the feed alley floor consisted of walking the entire length of the feed bunk alley 20 min before and after scraping, and measuring the height of manure that collected on the heel of rubber boots. Floor cleanliness was evaluated as clean $(\leq 0.5 \mathrm{~cm}$ manure), a bit dirty $(>0.5$ to

Table 1. Characteristics (mean $\pm \mathrm{SD}$ ) of 141 freestall dairy farms and the average freestall farm in 3 Canadian provinces

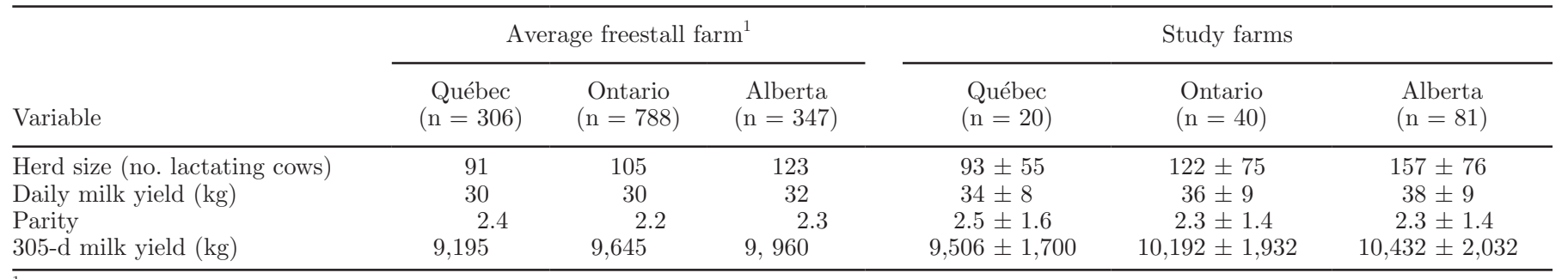

${ }^{1}$ Data from 2012. Source: CanWest DHI (Guelph, ON, Canada). 
$\leq 1 \mathrm{~cm})$, dirty $(1$ to $3 \mathrm{~cm})$, or very dirty $(>3 \mathrm{~cm})$. If the scraping system was manual, feed alley cleanliness was scored at the beginning and at the end of the visit. Slipperiness was assessed using the scoring system adapted from Grandin (2008). Slipperiness was estimated as the proportion of cows that slipped or fell when a minimum of 20 cows were observed, or when the pen was observed for up to $30 \mathrm{~min}$ while the herd manager moved the cows to the milking parlor. A slip was noted each time the cow's feet slid as they touched the floor. A fall was noted when at least 1 knee (carpus) or hock (tarsus) touched the floor (Rushen and de Passillé, 2006). Floor conditions were evaluated as nonslippery (no slipping or falling), slightly slippery ( $\leq 3 \%$ of cows slipped), slippery ( $<2 \%$ fall or 3 to $15 \%$ slip), or very slippery $(\geq 2 \%$ fall or $\geq 15 \%$ slip).

Stall Management. Each pen where the study cows were housed was assessed for stocking density, stall dimensions, stall base, stall bedding type, cleanliness, quantity, and dryness. Information on stocking density was obtained as described (Charlton et al., 2014) and estimated as number of cows/usable stalls. Data on 8 dimensions per stall, bedding cleanliness, quantity, and dryness were estimated as described (Zaffino Heyerhoff et al., 2014; Vasseur et al., 2015). Briefly, stall dimensions were measured at the end stalls of 3 representative rows in each pen ( $\mathrm{n}=2$ stalls per row). If the pen had $<3$ rows, stall dimensions were measured from all rows. Lunge space was considered adequate if no obstruction was present $\leq 76 \mathrm{~cm}$ forward from the brisket board. If no brisket board was present, this measure was taken from the point of the neck rail and $10 \mathrm{~cm}$ above the stall surface. End stalls were usually narrower or wider than the average stall. Therefore, stall width was measured in the middle of each row (minimum 6 stalls per farm) as the average width of 3 adjacent stalls. Bedding quantity was evaluated as the bedding depth (in $\mathrm{cm}$ ) after the stall was raked evenly, and was evaluated as $\leq 2 \mathrm{~cm}$ (equivalent to $1 \mathrm{~kg}$ of chopped straw), or $>2 \mathrm{~cm}$. The type of stall base and bedding were also recorded. If different types of stall bases were present in the same pen, the predominant stall base type was considered. Sand was only recorded as a bedding type when it was also the stall base.

Footbath. Length, depth, and width were measured for every footbath used. Detailed information was collected from the questionnaire on the frequency of use (times/wk), frequency of changing solutions, as well as products used and their concentrations.

\section{Statistical Analyses}

All statistical analyses were performed using Stata13.1 (StataCorp, 2013, College Station, TX) and $P$
$<0.05$ was considered significant. Descriptive statistics (mean, median, range, interquartile range) were used to describe herd- and cow-level characteristics, using farm and cow, respectively, as the experimental unit. Continuous predictor variables were tested for linearity.

Analyses of hock injuries and claw length (cow level) were done using the higher score of the 2 limbs. If the lactating cows were housed in 2 or more pens and these pens differed in flooring or stall characteristics, the pen with the highest number of study cows was selected for analysis. If an equal number of cows was housed in each pen, 1 of the 2 pens was randomly selected. Similarly, if $\geq 2$ footbaths were not identical, random selection was performed. Categorical variables with low frequency ( $\leq 4$ farms) were collapsed based on biological reasoning (i.e., an exact scraping frequency could not be determined for farms with a robotic scraper, therefore they were categorized as $>2$ times/d). Unusual stall bases, bedding types, and floorings that could not make their own category in analysis due to a low sample size were considered in a category as "other" (Zaffino Heyerhoff et al., 2014). If 2 predictors were highly correlated ( $|\mathrm{r}|$ $\geq 0.7$ ), the one with the strongest association with the outcome or the one with the fewest missing observations was chosen.

The model building process involved 3 steps. First, univariable analyses were performed to assess associations between the outcome of interest, presence of lameness at cow level, and each predictor variable. Predictors with a univariate association with $P \leq$ 0.25 were considered for the next step of multivariable modeling within 4 categories of explanatory variables: individual cow measures, pen space and flooring, stall management, and footbath management. In the second step, explanatory variables were screened in 4 separate multilevel mixed logistic regression models (GLMM in Stata). In this step, all variables significant at $P \leq$ 0.10 from the 4 models were combined, and a backward elimination process was performed. Variables significant at $P<0.05$ were retained in the final model. Additionally, if confounding was present (i.e., removal of any variable resulted in a $30 \%$ change in the estimate of any other significant predictor), then that variable was also retained in the final model. Two-way interactions (e.g., bedding quantity and type of bedding, floor slipperiness and type of flooring, parity and DIM, and BCS and DIM) were tested among the significant predictors in the main effects model, but none was retained $(P$ $>0.05$ in all cases). Farm was included as a random effect, and province was forced into the final regression model as a fixed effect. Model comparison among all multivariable models was based on Akaike's information criterion, and the model with the lowest Akaike's 
information criterion was considered the best model (Akaike, 1973).

\section{RESULTS}

Study farms had on average 124 lactating cows, with daily and 305-d milk production of 36 and $10,238 \mathrm{~kg}$, respectively (Table 1). Farm characteristics of this study represented the overall population of cows housed in freestalls per province in terms of parity, although herd size and milk production were slightly greater, because our study criteria required herds with $\geq 40$ cows and cows between 10 and 120 DIM. All farms in QC had only 1 pen, whereas in $\mathrm{ON}$ and $\mathrm{AB}$, a total of 70 farms $(50 \%)$ had 2 or 3 pens from which cows were sampled.

The exact agreement between the 2 trainers for locomotion scoring was $\geq 82 \%$ throughout the study period. The exact agreement for the 6 observers across provinces was $94 \%\left(\mathrm{~K}_{\mathrm{w}} \geq 0.8\right)$ for lame versus not lame. A total of 5,637 cows were observed with 5,256 cows having complete lameness scoring. Herd-level lameness prevalence ranged from 0 to $69 \%$ with a mean of $20.8 \%$ on the 141 farms. A larger variation of lameness prevalence was found among farms than among provinces. Mean herd lameness estimates within province ranged from 2 to $69 \%, 0$ to $62 \%$, and 8 to $61 \%$ for $\mathrm{AB}, \mathrm{ON}$, and $\mathrm{QC}$, respectively; mean prevalences were $19 \%(\mathrm{AB})$, $22 \%(\mathrm{ON})$, and $24 \%(\mathrm{QC})$. The $10 \%$ of herds with the lowest lameness prevalence had a prevalence $<8 \%$, whereas in the $10 \%$ herds with the highest prevalence, $>35 \%$ of the cows were lame.

\section{Cow-Level Variables}

Lameness prevalence increased with increasing parity and it differed among parities in univariable analysis $(P<0.001$, Figure 2$)$. The lowest lameness prevalence $(<14$ and $<18 \%)$ occurred in first and second parity cows respectively, which combined represented $65 \%$ of the study cows. A $10 \%$ point increase was present in lameness prevalence from second to third parity cows, whereas cows in 4th or higher parity had a lameness prevalence $\geq 32 \%$ [prevalence was highest $(38 \%)$ for cows with parities $\geq 7$. The majority of cows (93\%) included in the study were $<200$ DIM. Lameness increased with increasing DIM in the univariable analysis $(P=0.002$, Table 2$)$. However, the difference in mean DIM between lame and nonlame cows was small. Cows with a low BCS had the highest lameness prevalence (Figure 3); $46 \%$ of the cows with BCS $\leq 2$ were lame, whereas approximately $15 \%$ of the cows with $\mathrm{BCS} \geq 3$ were lame. Lameness was associated with lower milk production, overgrown claws, and hock injuries (Table $2)$.

\section{Herd-Level Variables}

A footbath was routinely used in 122 farms (87\%). A range of 1 to 4 products were used per farm, the most common being $\mathrm{CuSO}_{4}$ and formaldehyde, with median concentrations of $4.5 \%$ (range, 0.3 to $12.5 \%$ ) and $5 \%$ (range, 1 to 10\%). Barn design and lameness-associated management practices varied greatly among farms (Tables 3, 4, and 5). Lameness prevalence increased with decreasing herd size; herds with $\leq 100$ and $>100$ cows had a mean lameness prevalence of 24 and $19 \%$, respectively $(P<0.001)$. The majority of farms $(70 \%)$ had a stocking density $\leq 100 \%$ (i.e., more stalls than cows), and lameness prevalence was not associated with overstocking $(P=0.32)$. Scraping system (automatic or manual) and scraping frequency were highly correlated ( $\mathrm{r}=0.83 ; P<0.001)$ because all farms that used a manual system scraped $\leq 3$ times/d. Holding pen flooring was correlated with feed alley flooring $(\mathrm{r}=0.35 ; P$ $<0.001)$. Herd size was correlated with footbath use $(\mathrm{r}$ $=0.43 ; P<0.001)$ because $95 \%$ of the farms that did not use a footbath were herds $\leq 100$ cows.

\section{Multivariable Analysis}

Based on univariable analyses, cow-level variables initially included in the multivariable model were parity, DIM, test-day milk production, claw length, leg cleanliness, hock injury, and BCS. Herd-level variables were herd size, stall bed length, lunge space, stall base, bedding type, bedding quality and quantity, frequency of bedding and stall cleaning, scraping frequency, feed alley width and flooring type, slipperiness of the flooring, footbath length, frequency of use, and number of footbath products (Table 6). A total of $7 \%$ of the model variability was at the farm level, whereas $93 \%$ of the variation was at the cow level. Cows with low BCS, injured hocks, and overgrown claws had a higher prevalence of lameness. Cows in parity $\geq 3$ had 3 times the odds of being lame compared with primiparous cows. Furthermore, every $1 \mathrm{~kg}$ increase in test-day milk production was associated with a $3 \%$ decrease in the odds of being lame. Cows in groups with a high prevalence of slips or falls had 2 times greater odds of being lame (Table 6). The odds of lameness were higher in cows housed with concrete or rubber stall bases than those housed with sand or dirt stall bases, as well as among cows housed with stalls with $\leq 2 \mathrm{~cm}$ of bedding, compared with those with stalls with $>2 \mathrm{~cm}$ of bedding.

\section{DISCUSSION}

Results from this study represented the population of Holstein-Friesian cows housed in freestalls without 


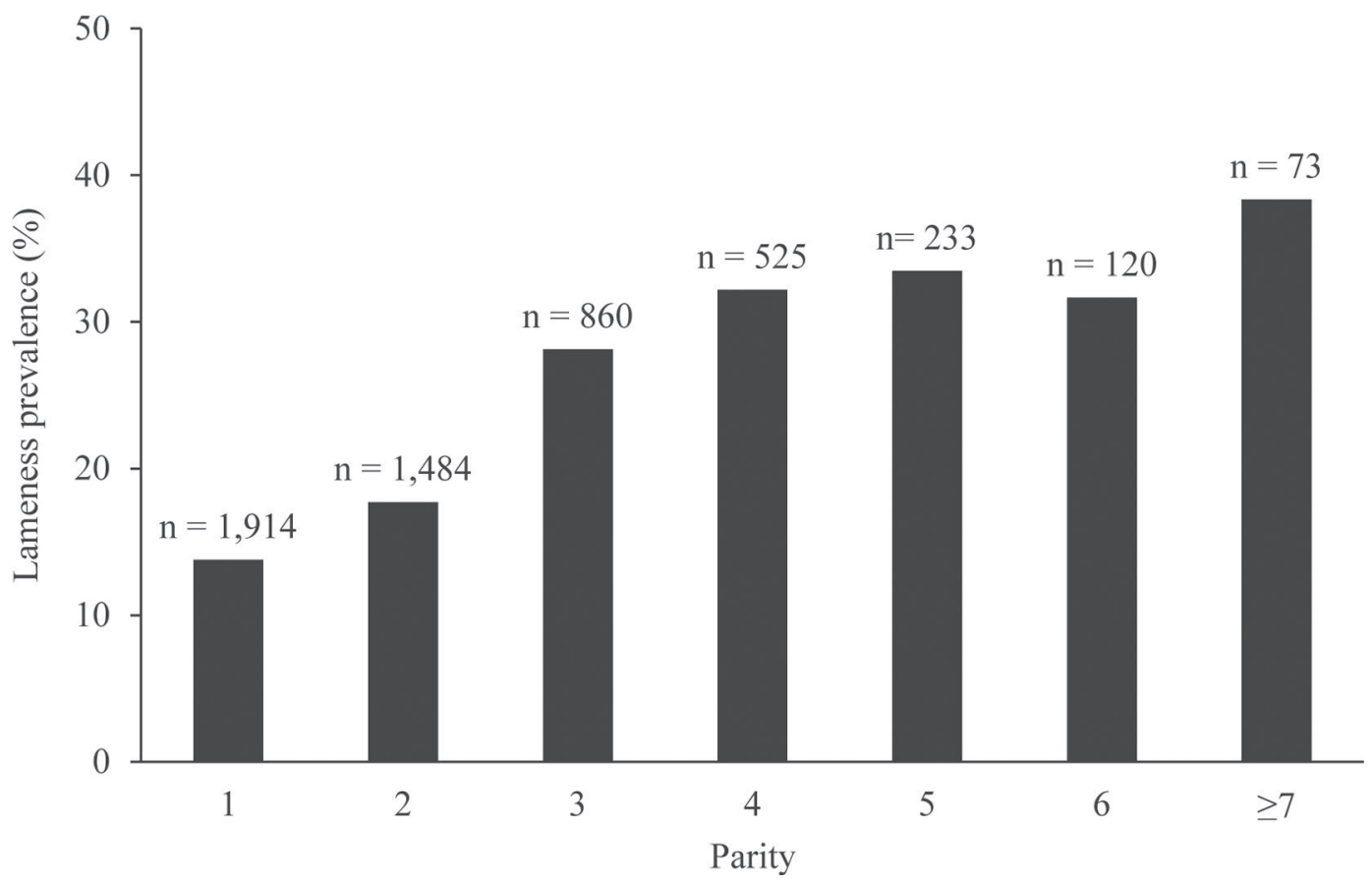

Figure 2. Percentage of lame cows per parity $(\mathrm{n}=$ number of cows per category).

pasture access in the 3 Canadian provinces that represent $79 \%$ of the total Canadian dairy cow population. The lameness prevalence of $21 \%$ reported in this study seemed comparable with that reported in Wisconsin and Minnesota (25\%; Cook, 2003; Espejo et al., 2006), England (22\%; Whay et al., 2003), and Finland (21\%; Sarjokari et al., 2013). However, the lameness prevalence estimate in the present study was lower than findings in British Columbia, California, and the northeastern United States $(35,34$, and $63 \%$, respectively; von Keyserlingk et al., 2012), conventional farms in central Germany (48\%; Dippel et al., 2009), and the United Kingdom (40\%; Barker et al., 2010).

Apparent differences in lameness prevalence estimates among regions could be the consequence of factors known to affect prevalence, such as herd size (e.g., mean herd size in California and Germany was 1,796 and 54 cows, respectively) and certain management practices (e.g., $100 \%$ of herds in California had deepbedded stalls, whereas $55 \%$ of herds in the northeastern US had stalls with little bedding). Additionally, differences in lameness estimates in these regions could also be the consequence of the lameness scoring system used (e.g., assessment of an arched back versus assessment of a cow's locomotion), interobserver reliability for lameness scoring (e.g., studies in the UK and Finland did not report interobserver assessments), and cow selection criteria (e.g., selection based on DIM, milk production, or parity).
In the present study, the odds of lameness increased with increasing parity, consistent with other studies (Espejo et al., 2006; Sarjokari et al., 2013). In agreement with Sarjokari et al. (2013), this association may be because older cows are bigger, are predisposed to relapse with certain foot lesions, and have been exposed for a longer interval to the housing environment than younger cows. In the present study, greater odds of lameness at a single assessment were associated with lower BCS on the same day and lower test-day milk production. Lameness assessment and milk recording did not always occur on the same day, possibly resulting in under- or overestimation of milk production. Various hypotheses have been made regarding the cause-and-effect relationship between BCS and lameness. Some authors suggested that low BCS was a result of lameness (attributed to a reduction of feed intake that caused BW loss; Espejo et al., 2006), whereas others suggested that low BCS contributed to lameness due to a decrease in thickness of the digital cushion, which caused foot lesions such as sole ulcers and white line disease (Bicalho et al., 2009). Studies also differed on the relationship between milk production and the risk of lameness. In some studies, an increased risk of lameness was present that was associated with either low (Warnick et al., 2001; Green et al., 2002) or high (Amory et al., 2008) milk production, whereas others reported no association (Haskell et al., 2006). However, these 
RISK FACTORS FOR LAMENESS IN CANADA

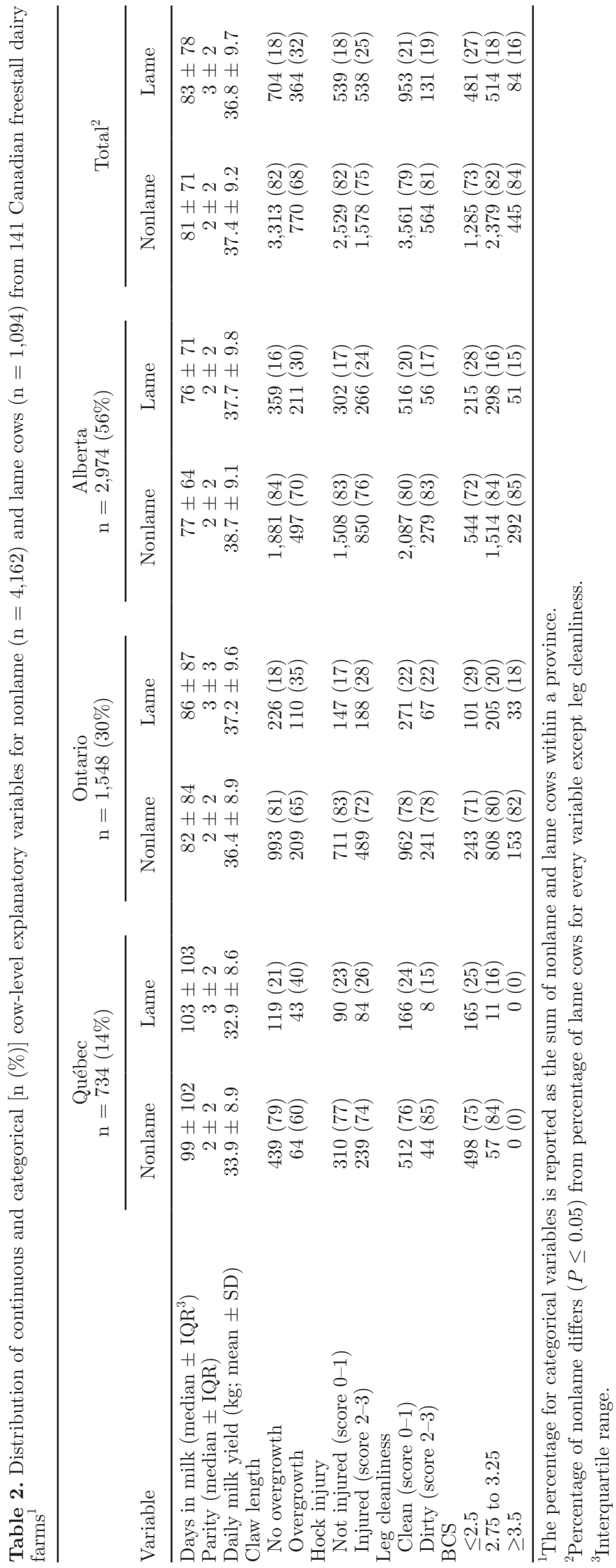




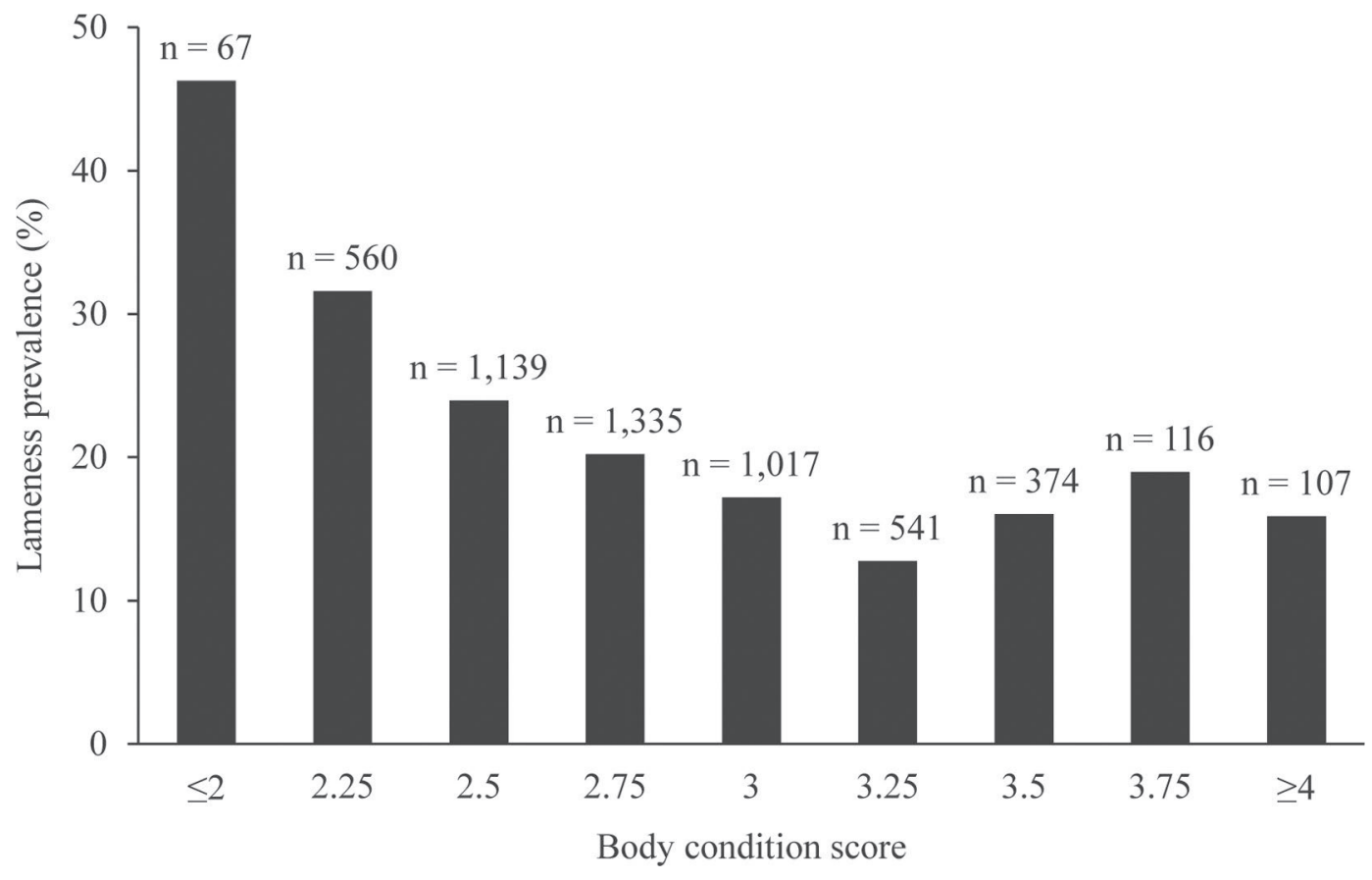

Figure 3. Percentage of lame cows per BCS category ( $\mathrm{n}=$ number of cows per category).

relationships may be confounded by stage of lactation and parity, among other variables.

We inferred that the complex associations between BCS, milk production and lameness vary depending on underlying conditions (e.g., infectious versus noninfectious foot lesions, or upper leg lameness) and need to be examined in large-scale longitudinal studies to distinguish risk factors for the incidence of new cases and persistence of lameness. In a longitudinal study (Green et al., 2014), BCS was highly variable throughout lactation (typically decreased in early lactation but increased in late lactation); furthermore, cows with low BCS $(<2.5)$ were more prone to develop lameness caused by noninfectious foot lesions and milk production decreased before cows became clinically lame.

The odds of lameness were significantly higher for cows with injured hocks. This association was explained in detail by Zaffino Heyerhoff et al. (2014), in which a subset of the present data was analyzed, suggesting that lame cows had difficulty lying down or getting up, resulting in abrasion of the hock area. However, as the direction of risk cannot be determined in a cross-sectional study, it may also be that hock lesions were painful enough to make the cows lame. The odds of lameness significantly increased for cows with overgrown claws compared with cows with a normal claw angle. In a report on the association between foot lesions and claw measurements (Manske, 2002), lame cows had longer, shallower, and more concave claws than nonlame cows and claw conformation varied according to the underlying foot lesion. Overgrown claws can also be a result of reduced wear (e.g., exposure to rubber flooring) and inconsistent hoof trimming.

Several aspects related to stalls were studied, including stall dimensions, cleanliness, dryness, type of bedding, and management practices related to bedding and cleaning frequency. Nevertheless, statistically significant associations were present only between lameness prevalence and bedding depth and sand or dirt stall bases, highlighting the importance of comfort of the lying surface with respect to lameness. However, no correlation was found between the type of bedding and its quantity. Additionally, a great variation in bedding type was present, resulting in a lack of power to study the effect of an interaction between bedding type and quantity.

Lower lameness prevalence has been reported in farms with sand bedding and deep bedding stalls compared with mattresses or little bedding (Cook et al., 2004b; Ito et al., 2010; Chapinal et al., 2013). It is generally understood that deep bedding provides a comfortable lying surface that affects the lying behavior of lame cows, influencing their recovery and thus decreasing the risk of lameness (Cook et al., 2008). However, the majority of farms in the current study $(60 \%)$ managed their stalls with small amounts of bedding and a minority (11\%) used sand or dirt as stall bases. Certainly, sand bases are not common in Canada, perhaps due 
to challenges related to manure handling with the use of sand, and aggravated by long and harsh winters. Hence, it is encouraging that deep bedding had a protective effect on lameness in the present study, as this may motivate more farmers to adopt this management practice. Furthermore, depth of bedding was important regardless of stall base, emphasizing that cow comfort has an important role in lameness prevalence.

Lameness prevalence was not associated with floor type in the milking parlor, holding pen, or feed alley. However, the odds of lameness were much higher on farms with very slippery flooring compared with nonslippery flooring. Evidence on the effect of different types of flooring on lameness prevalence has been equivocal. Concrete flooring is known to have a detrimental effect on foot health when compared with straw yards or pasture (Somers et al., 2003); however, no clear evidence was found of the effect of various types of concrete flooring on lameness. Somers et al. (2003) reported no associations between solid or slatted concrete floors and prevalence of noninfectious foot lesions, whereas Sogstad et al. (2005a) reported a higher risk for white line disease on slatted floors.

Although benefits of rubber flooring on the locomotion of lame and nonlame cows (i.e., increased length of steps and speed) have been reported (Telezhenko and Bergsten, 2005), no clear evidence was present on the risk of developing foot lesions in cows exposed to rubber versus concrete flooring. Vanegas et al. (2006) reported that foot lesions did not differ between floor types, although the odds of becoming lame were greater for concrete-exposed cows. In contrast, Kremer et al. (2007) reported a higher incidence of sole ulcers on cows exposed to rubber flooring compared with concrete. It

Table 3. Distribution of continuous (mean $\pm \mathrm{SD}$ ) and categorical $[\mathrm{n}(\%)]$ herd-level stall management variables for dairy herds with a low, medium, or high lameness prevalence

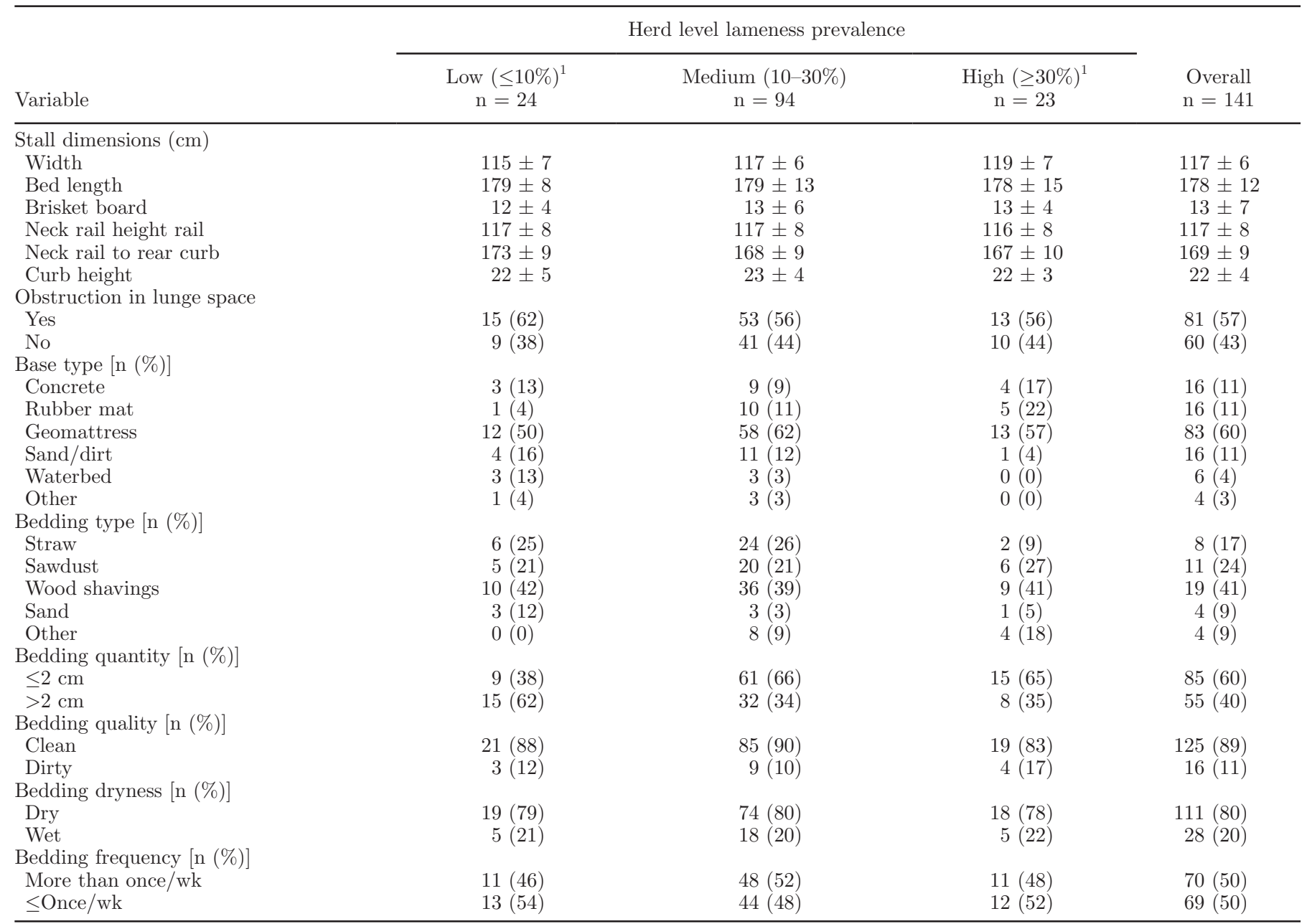

${ }^{1}$ Categories defined by the 20th and 80th percentile of herd lameness prevalence on a single assessment of a purposive sample of 40 cows per herd in 141 herds. 
Table 4. Distribution of categorical [n (\%)] herd-level flooring variables for dairy herds with a low, medium, or high lameness prevalence

\begin{tabular}{|c|c|c|c|c|}
\hline Variable & \multicolumn{3}{|c|}{ Herd level lameness prevalence } & $\begin{array}{c}\text { Overall } \\
\mathrm{n}=141\end{array}$ \\
\hline$<350$ & $4(17)$ & $21(22)$ & $8(35)$ & $33(23)$ \\
\hline$\geq 350$ & $20(83)$ & $73(78)$ & $15(65)$ & $108(72)$ \\
\hline \multicolumn{5}{|l|}{ Scraping frequency (times/d) } \\
\hline \multicolumn{5}{|l|}{ Parlor flooring } \\
\hline Solid concrete & $13(54)$ & $67(71)$ & $15(65)$ & $95(67)$ \\
\hline Solid rubber & $11(46)$ & $27(29)$ & $8(35)$ & $46(33)$ \\
\hline \multicolumn{5}{|l|}{ Holding pen flooring } \\
\hline Solid concrete & $11(48)$ & $53(61)$ & $11(50)$ & $75(57)$ \\
\hline Slatted concrete & $2(9)$ & $6(7)$ & $2(9)$ & $10(8)$ \\
\hline Solid rubber & $8(34)$ & $23(26)$ & $5(23)$ & $36(27)$ \\
\hline \multicolumn{5}{|l|}{ Feed alley cleanliness } \\
\hline Clean & $14(61)$ & $55(59)$ & $12(55)$ & $81(59)$ \\
\hline Dirty & $9(39)$ & $38(41)$ & $10(45)$ & $57(41)$ \\
\hline \multicolumn{5}{|l|}{ Slipperiness (\% cows) } \\
\hline Nonslippery (no slipping) & $16(70)$ & $48(57)$ & $10(45)$ & $74(57)$ \\
\hline Slightly slippery ( $\leq 3 \%$ slip) & $4(17)$ & $22(26)$ & $6(27)$ & $32(25)$ \\
\hline Slippery ( $<2 \%$ fall to $3-15 \%$ slip $)$ & $3(13)$ & $13(14)$ & $3(14)$ & $19(15)$ \\
\hline Very slippery ( $\geq 2 \%$ fall to $\geq 15 \%$ slip $)$ & $0(0)$ & $1(1)$ & $3(14)$ & $4(3)$ \\
\hline
\end{tabular}

${ }^{1}$ Categories defined by the 20 th and 80 th percentile of herd lameness prevalence on a single assessment of a purposive sample of 40 cows per herd in 141 herds.

is noteworthy that these findings may be confounded by variables including stall design, bedding type and depth, and stocking density.
Manure, slurry, and wet flooring conditions are predisposing factors to increased floor slipperiness. In this study, lameness prevalence was not associated with

Table 5. Distribution of continuous (median \pm interquartile range, IQR) and categorical [n (\%)] footbath management variables for dairy herds with a low, medium, or high lameness prevalence that use regular footbathing

\begin{tabular}{|c|c|c|c|c|}
\hline Variable & \multicolumn{3}{|c|}{ Herd level lameness prevalence } & $\begin{array}{c}\text { Overall } \\
\mathrm{n}=122\end{array}$ \\
\hline \multicolumn{5}{|l|}{ Footbath product $[\mathrm{n}(\%)]$} \\
\hline $\mathrm{CuSO}_{4}$ & $8(38)$ & $30(38)$ & $7(35)$ & $45(37)$ \\
\hline Formaldehyde & $1(5)$ & $13(16)$ & $4(20)$ & $18(15)$ \\
\hline $\mathrm{CuSO}_{4}$ and formaldehyde & $11(52)$ & $32(40)$ & $7(35)$ & $50(41)$ \\
\hline 1 & $6(29)$ & $33(41)$ & $7(35)$ & $46(38)$ \\
\hline 2 & $12(57)$ & $35(44)$ & $10(50)$ & $57(47)$ \\
\hline$\geq 3$ & $3(14)$ & $12(15)$ & $3(15)$ & $18(15)$ \\
\hline \multicolumn{5}{|c|}{ Footbath frequency of use $[\mathrm{n}(\%)]$} \\
\hline$\leq 2 \mathrm{~d} / \mathrm{wk}$ & $8(38)$ & $41(51)$ & $10(50)$ & $59(48)$ \\
\hline$>2 \mathrm{~d} / \mathrm{wk}$ & $13(62)$ & $40(49)$ & $10(50)$ & $63(52)$ \\
\hline \multicolumn{5}{|c|}{ Footbath dimension (median $\pm \mathrm{IQR}$ ) } \\
\hline
\end{tabular}

${ }^{1}$ Categories defined by the 20th and 80th percentile of herd lameness prevalence on a single assessment of a purposive sample of 40 cows per herd in 141 dairy herds. 
floor cleaning routines nor feed alley cleanliness. However, floor cleanliness was only assessed on 1 occasion. Perhaps direct observation of cows slipping or falling was a better indicator of floor conditions than recording information on floor cleanliness. Notwithstanding, the results of the present study highlighted that the type of flooring (rubberized or concrete, slatted or solid) was less relevant than the flooring's slip resistance. However, slipperiness indicator in the present study may have been confounded by cattle handling. Poor cattle handling (rushed or aggressive handling) and slippery floors can result in injuries from slipping or falling and may be a predisposing factor for foot lesions due to alterations in cow gait.

Lameness prevalence was not associated with footbathing practices, nor with footbath measurements. Besides a possible lack of statistical power, this result may reflect the fact that certain footbathing practices can increase lameness and that high lameness prevalence can also incite certain footbathing practices. The same applies to other management practices such as stall bedding frequency or floor scraping frequency.
Therefore, more prospective, longitudinal studies are needed to assess these variables as contributors to the onset, duration, and resolution of lameness.

Potential bias introduced by observers was controlled by the standard operating procedures developed, the intensive training program, and periodic checks throughout the study; collectively, these apparently contributed to achievement of high interobserver agreement. However, controlling for observer had no added value, as observers in $\mathrm{ON}$ and $\mathrm{AB}$ were not specific per farm (i.e., $\leq 2$ observers were involved per farm), and in QC only 1 observer was present. In the statistical analysis, province did not result as a confounder and it was forced as a fixed effect in the models; furthermore, no large difference was present among provinces' overall lameness estimates. Therefore, we were confident of the reliability of the lameness estimate in our study.

A strength of the present study was the large number of cows and farms and the comprehensive set of variables assessed. However, the cross-sectional nature of the data collection revealed numerous associations with lameness, but limited our ability to make causal infer-

Table 6. Final multilevel logistic regression model for lameness with cow and herd-level factors in 141 Canadian dairy herds $(\mathrm{n}=4,981)$

\begin{tabular}{|c|c|c|c|c|}
\hline Variable & Coefficient & $\begin{array}{l}\text { Odds } \\
\text { ratio }\end{array}$ & $95 \% \mathrm{CI}$ & $P$-value \\
\hline \multicolumn{5}{|l|}{ Parity } \\
\hline 1 & Referent & & & \\
\hline 2 & 0.48 & 1.62 & $1.29-2.02$ & $<0.001$ \\
\hline 3 & 1.19 & 3.28 & $2.56-4.19$ & $<0.001$ \\
\hline$\geq 4$ & 1.38 & 3.96 & $3.11-5.03$ & $<0.001$ \\
\hline Daily milk production (kg) & -0.03 & 0.97 & $0.96-0.98$ & $<0.001$ \\
\hline \multicolumn{5}{|l|}{$\mathrm{BCS}$} \\
\hline$\leq 2.5$ & Referent & & & \\
\hline $2.75-3.25$ & -0.45 & 0.64 & $0.52-0.77$ & $<0.001$ \\
\hline$\geq 3.5$ & -0.66 & 0.51 & $0.37-0.71$ & $<0.001$ \\
\hline \multicolumn{5}{|l|}{ Hock injury } \\
\hline Not injured (score $0-1$ ) & Referent & & & \\
\hline Injured (score 2-3) & 0.35 & 1.41 & $1.19-1.67$ & $<0.001$ \\
\hline \multicolumn{5}{|l|}{ Claw length } \\
\hline No overgrowth & Referent & & & \\
\hline Overgrowth & 0.57 & 1.77 & $1.47-2.12$ & $<0.001$ \\
\hline \multicolumn{5}{|l|}{ Herd size (no. of lactating cows) } \\
\hline$\leq 100$ & Referent & & & \\
\hline$>100$ & -0.39 & 0.67 & $0.51-0.89$ & 0.005 \\
\hline \multicolumn{5}{|l|}{ Stall base } \\
\hline Concrete & Referent & & & \\
\hline Rubber mattress & 0.15 & 1.17 & $0.71-1.91$ & 0.550 \\
\hline Geotextile mattress & -0.23 & 0.77 & $0.51-1.16$ & 0.212 \\
\hline Sand/dirt & -0.64 & 0.53 & $0.30-0.94$ & 0.029 \\
\hline Waterbed & -0.60 & 0.55 & $0.26-1.15$ & 0.111 \\
\hline Other & -0.48 & 0.62 & $0.29-1.32$ & 0.214 \\
\hline \multicolumn{5}{|l|}{ Bedding quantity } \\
\hline$\leq 2 \mathrm{~cm}$ & Referent & & & \\
\hline$>2 \mathrm{~cm}$ & -0.29 & 0.74 & $0.55-0.99$ & 0.050 \\
\hline \multicolumn{5}{|l|}{ Slipperiness } \\
\hline Nonslippery (no slipping) & Referent & & & \\
\hline Slightly slippery ( $\leq 3 \%$ slip$)$ & 0.32 & 1.38 & $1.03-1.86$ & 0.032 \\
\hline Slippery $(<2 \%$ fall to $3-15 \%$ slip $)$ & -0.01 & 0.99 & $0.68-1.43$ & 0.970 \\
\hline Very slippery ( $\geq 2 \%$ fall to $\geq 15 \%$ slip) & 0.75 & 2.12 & $1.07-4.16$ & 0.031 \\
\hline
\end{tabular}


ences. Several factors may have limited the generalizability of our results. Study farms were not randomly selected, they were visited during different seasons, and different farm selection methods were used among provinces. For example, farms in Alberta were selected based on participation in a hoof trimming project. Although trimming practices are known to be an important risk factor for lameness (Cramer et al., 2009), this was not included as a factor in our analyses because it was linked to the study's selection criteria and therefore could not be assessed in an unbiased manner. Therefore, a potential bias due to selection and seasonality may have affected the lameness prevalence estimate, although probably not the risk factors identified. The method used for cow selection was not random, as it targeted early- to mid-lactation cows (high-producing group) that are at high risk for lameness (Green et al., 2002). However, the study findings supported several of the hypotheses in our causal diagram and were in agreement with other studies from North America (Espejo et al., 2006) and Europe (Sarjokari et al., 2013). In that regard, we inferred that our study provided valid and generalizable results to North American freestall dairies without pasture access.

\section{CONCLUSIONS}

This was apparently the largest study conducted to determine lameness prevalence and associated risk factors in dairy cows in Canada. We attributed the wide range of lameness prevalence to the great variability in facilities and management practices among farms. Improving management of multiparous, thin, or injured cows and adopting management practices intended to improve cow comfort, namely the floor's slip resistance and the stall's lying surface, should reduce the prevalence of lameness.

\section{ACKNOWLEDGMENTS}

The authors thank participating farmers, collaborators, technicians, students, and co-op students from $\mathrm{Ag}$ riculture \& Agri-Food Canada (Agassiz, BC, Canada), University of British Columbia, University of Calgary, University of Guelph, Université Laval, Utrecht University (the Netherlands), HAS University of Applied Sciences (the Netherlands), CanWest DHI, and Valacta. We are especially grateful for the contributions of Guilherme Bond and Tanja Kraus (University of Calgary) in data collection. We thank Jenny Gibbons (DairyCo UK) and Gemma Charlton (Harper Adams College, UK) for invaluable help with establishing the database. We also thank John Kastelic (Department of Production Animal Health, University of Calgary,
AB, Canada) for editing this manuscript. This study was funded by Dairy Farmers of Canada (Ottawa, ON, Canada), the Canadian Dairy Commission (Ottawa, ON, Canada), Agriculture and Agri-Food Canada, as part of the Dairy Science Cluster initiative, Alberta Milk (Edmonton, AB, Canada), and the Alberta Livestock and Meat Agency (Edmonton, AB, Canada).

\section{REFERENCES}

Akaike, H. 1973. Information theory and an extension of the maximum likelihood principle. Pages 267-281 in 2nd Int. Symp. Inf. Theory. Akademiai Kiado, Budapest, Hungary.

Alberta Milk. 2013. Dairy cattle hoof health. Accessed Jun. 18, 2015. http://dairyhoofhealth.info/lesions/hoof-lesion-prevalence-in3-canadian-provinces/.

Amory, J. R., Z. E. Barker, J. L. Wright, S. A. Mason, R. W. Blowey, and L. E. Green. 2008. Associations between sole ulcer, white line disease and digital dermatitis and the milk yield of 1824 dairy cows on 30 dairy cow farms in England and Wales from February 2003-November 2004. Prev. Vet. Med. 83:381-391.

Amory, J. R., P. Kloosterman, Z. E. Barker, J. L. Wright, R. W. Blowey, and L. E. Green. 2006. Risk factors for reduced locomotion in dairy cattle on nineteen farms in the Netherlands. J. Dairy Sci. 89:1509-1515.

Barker, Z. E., K. A. Leach, H. R. Whay, N. J. Bell, and D. C. J. Main. 2010. Assessment of lameness prevalence and associated risk factors in dairy herds in England and Wales. J. Dairy Sci. 93:932-941.

Bicalho, R. C., V. S. Machado, and L. S. Caixeta. 2009. Lameness in dairy cattle: A debilitating disease or a disease of debilitated cattle? A cross-sectional study of lameness prevalence and thickness of the digital cushion. J. Dairy Sci. 92:3175-3184.

Booth, C. J., L. D. Warnick, Y. T. Gröhn, D. O. Maizon, C. L. Guard, and D. Janssen. 2004. Effect of lameness on culling in dairy cows. J. Dairy Sci. 87:4115-4122.

Canadian Dairy Information Centre. 2014. Dairy facts and figures. Accessed Jun. 18, 2015. http://www.dairyinfo.gc.ca.

Chapinal, N., A. K. Barrientos, M. A. G. von Keyserlingk, E. Galo, and D. M. Weary. 2013. Herd-level risk factors for lameness in freestall farms in the northeastern United States and California. J. Dairy Sci. 96:318-328.

Chapinal, N., A. M. de Passillé, D. M. Weary, M. A. G. von Keyserlingk, and J. Rushen. 2009. Using gait score, walking speed, and lying behavior to detect hoof lesions in dairy cows. J. Dairy Sci. 92:4365-4374.

Charlton, G. L., D. B. Haley, J. Rushen, and A. M. de Passillé. 2014. Stocking density, milking duration, and lying times of lactating cows on Canadian freestall dairy farms. J. Dairy Sci. 97:2694-2700.

Cook, N. B. 2003. Prevalence of lameness among dairy cattle in Wisconsin as a function of housing type and stall surface. J. Am. Vet. Med. Assoc. 223:1324-1328.

Cook, N. B. 2006. Footbath alternatives. Accessed Jun. 18, 2015. http://www.vetmed.wisc.edu/dms/fapm/fapmtools/6lame/ Footbath_Alternatives.pdf.

Cook, N. B., T. B. Bennett, and K. V. Nordlund. 2004a. Effect of free stall surface on daily activity patterns in dairy cows with relevance to lameness prevalence. J. Dairy Sci. 87:2912-2922.

Cook, N. B., M. J. Marin, R. L. Mentink, T. B. Bennett, and M. J. Schaefer. 2008. Comfort zone-design free stalls: Do they influence the stall use behavior of lame cows? J. Dairy Sci. 91:4673-4678.

Cook, N. B., K. V. Nordlund, and G. R. Oetzel. 2004b. Environmental influences on claw horn lesions associated with laminitis and subacute ruminal acidosis in dairy cows. J. Dairy Sci. 87(Suppl.):E36E46.

Cramer, G., K. D. Lissemore, C. L. Guard, K. E. Leslie, and D. F. Kelton. 2009. Herd-level risk factors for seven different foot lesions in Ontario Holstein cattle housed in tie stalls or free stalls. J. Dairy Sci. 92:1404-1411. 
Dippel, S., M. Dolezal, C. Brenninkmeyer, J. Brinkmann, S. March, U. Knierim, and C. Winckler. 2009. Risk factors for lameness in freestall-housed dairy cows across two breeds, farming systems, and countries. J. Dairy Sci. 92:5476-5486.

Espejo, L. A., and M. I. Endres. 2007. Herd-level risk factors for lameness in high-producing Holstein cows housed in freestall barns. J. Dairy Sci. 90:306-314.

Espejo, L. A., M. I. Endres, and J. A. Salfer. 2006. Prevalence of lameness in high-producing Holstein cows housed in freestall barns in Minnesota. J. Dairy Sci. 89:3052-3058.

Ettema, J. F., and S. Ostergaard. 2006. Economic decision making on prevention and control of clinical lameness in Danish dairy herds. Livest. Sci. 102:92-106.

Flower, F. C., and D. M. Weary. 2006. Effect of hoof pathologies on subjective assessments of dairy cow gait. J. Dairy Sci. 89:139-146.

Garbarino, E. J., J. A. Hernandez, J. K. Shearer, C. A. Risco, and W. W. Thatcher. 2004. Effect of lameness on ovarian activity in postpartum Holstein cows. J. Dairy Sci. 87:4123-4131.

Gibbons, J., E. Vasseur, J. Rushen, and A. M. d. Passillé. 2012. A training programme to ensure high repeatability of injury scoring of dairy cows. Anim. Welf. 21:379-388.

Grandin, T. 2008. Cattle transport guidelines for meat packers, feedlots, and ranches. Accessed Jun. 18, 2015. http://www.grandin. $\mathrm{com} /$ meat.association.institute.html.

Green, L. E., V. J. Hedges, Y. H. Schukken, R. W. Blowey, and A. J. Packington. 2002. The impact of clinical lameness on the milk yield of dairy cows. J. Dairy Sci. 85:2250-2256.

Green, L. E., J. N. Huxley, C. Banks, and M. J. Green. 2014. Temporal associations between low body condition, lameness and milk yield in a UK dairy herd. Prev. Vet. Med. 113:63-71.

Haskell, M. J., L. J. Rennie, V. A. Bowell, M. J. Bell, and A. B. Lawrence. 2006. Housing system, milk production, and zero-grazing effects on lameness and leg injury in dairy cows. J. Dairy Sci. 89:4259-4266.

Hernandez, J., J. K. Shearer, and D. W. Webb. 2001. Effect of lameness on the calving-to-conception interval in dairy cows. J. Am. Vet. Med. Assoc. 218:1611-1614.

Hernandez-Mendo, O., M. A. G. von Keyserlingk, D. M. Veira, and D. M. Weary. 2007. Effects of pasture on lameness in dairy cows. J. Dairy Sci. 90:1209-1214.

Ito, K., M. A. G. von Keyserlingk, S. J. LeBlanc, and D. M. Weary. 2010. Lying behavior as an indicator of lameness in dairy cows. J. Dairy Sci. 93:3553-3560.

Ito, K., D. M. Weary, and M. A. G. von Keyserlingk. 2009. Lying behavior: Assessing within- and between-herd variation in free-stallhoused dairy cows. J. Dairy Sci. 92:4412-4420.

Kremer, P. V., S. Nueske, A. M. Scholz, and M. Foerster. 2007. Comparison of claw health and milk yield in dairy cows on elastic or concrete flooring. J. Dairy Sci. 90:4603-4611.

Manske, T. 2002. Hoof lesions and lameness in Swedish dairy cattle: Prevalence, risk factors, effects of claw trimming and consequences for productivity. Pages 68-68 in Vol. C825123. Sveriges Lantbruksuniversitet, Sweden.

Rushen, J., and A. M. de Passillé. 2006. Effects of roughness and compressibility of flooring on cow locomotion. J. Dairy Sci. 89:29652972 .
Rushen, J., E. Pombourcq, and A. M. de Passillé. 2007. Validation of two measures of lameness in dairy cows. Appl. Anim. Behav. Sci. 106:173-177.

Sarjokari, K., K. O. Kaustell, T. Hurme, T. Kivinen, O. A. T. Peltoniemi, H. Saloniemi, and P. J. Rajala-Schultz. 2013. Prevalence and risk factors for lameness in insulated free stall barns in Finland. Livest. Sci. 156:44-52.

Sogstad, A. M., T. Fjeldaas, and O. Østerås. 2005a. Lameness and claw lesions of the Norwegian red dairy cattle housed in free stalls in relation to environment, parity and stage of lactation. Acta Vet. Scand. 46:203-217.

Sogstad, A. M., T. Fjeldaas, O. Østerås, and K. P. Forshell. 2005b. Prevalence of claw lesions in Norwegian dairy cattle housed in tie stalls and free stalls. Prev. Vet. Med. 70:191-209.

Somers, J., K. Frankena, E. N. Noordhuizen-Stassen, and J. H. M. Metz. 2003. Prevalence of claw disorders in Dutch dairy cows exposed to several floor systems. J. Dairy Sci. 86:2082-2093.

Telezhenko, E., and C. Bergsten. 2005. Influence of floor type on the locomotion of dairy cows. Appl. Anim. Behav. Sci. 93:183-197.

Vanegas, J., M. Overton, S. L. Berry, and W. M. Sischo. 2006. Effect of rubber flooring on claw health in lactating dairy cows housed in free-stall barns. J. Dairy Sci. 89:4251-4258.

Vasseur, E., J. Gibbons, J. Rushen, and A. M. de Passillé. 2013. Development and implementation of a training program to ensure high repeatability of body condition scoring of dairy cows. J. Dairy Sci. 96:4725-4737.

Vasseur, E., J. Gibbons, J. Rushen, D. Pellerin, E. Pajor, D. Lefebvre, and A. M. de Passillé. 2015. An assessment tool to help producers improve cow comfort on their farms. J. Dairy Sci. 98:698-708.

Vermunt, J. J. 2007. One step closer to unravelling the pathophysiology of claw horn disruption: For the sake of the cows' welfare. Vet. J. 174:219-220.

von Keyserlingk, M. A. G., A. Barrientos, K. Ito, E. Galo, and D. M. Weary. 2012. Benchmarking cow comfort on North American freestall dairies: Lameness, leg injuries, lying time, facility design, and management for high-producing Holstein dairy cows. J. Dairy Sci. 95:7399-7408.

Warnick, L. D., D. Janssen, C. L. Guard, and Y. T. Gröhn. 2001. The effect of lameness on milk production in dairy cows. J. Dairy Sci. 84:1988-1997.

Whay, H. R., D. C. J. Main, L. E. Green, and A. J. F. Webster. 2003. Assessment of the welfare of dairy cattle using animal-based measurements: Direct observations and investigation of farm records. Vet. Rec. 153:197-202.

Whay, H. R., A. E. Waterman, A. J. F. Webster, and J. K. O'Brien. 1998. The influence of lesion type on the duration of hyperalgesia associated with hindlimb lameness in dairy cattle. Vet. J. 156:23-29.

Zaffino Heyerhoff, J. C., S. J. LeBlanc, T. J. DeVries, C. G. R. Nash, J. Gibbons, K. Orsel, H. W. Barkema, L. Solano, J. Rushen, A. M. de Passillé, and D. B. Haley. 2014. Prevalence of and factors associated with hock, knee, and neck injuries on dairy cows in freestall housing in Canada. J. Dairy Sci. 97:173-184.

Zurbrigg, K., D. Kelton, N. Anderson, and S. Millman. 2005. Stall dimensions and the prevalence of lameness, injury, and cleanliness on 317 tie-stall dairy farms in Ontario. Can. Vet. J. 46:902-909. 